\title{
THE SOCIO-ECONOMIC IMPACT OF THE REFUGEES ON EUROPE. COSTLY ON THE SHORT TERM, BENEFICIAL ON THE LONG RUN?
}

\section{Romana Emilia CRAMARENCO, PhD}

Lecturer, Faculty of European Studies, Babeş-Bolyai University, Romania romana.cramarenco@ubbcluj.ro

\begin{abstract}
We witness an unprecedented Age of Migration, with massive inflows of refugees in search for survival, escaping conflict and persecution in their home communities. In the last two years, migration as a whole, and asylum and border management in particular, were put under severe pressure, with a relevant input given by media coverage in Europe, often portraying refugees as main source of instability in EU - "marginalization makes them easy targets for scapegoating by far right parties, which have gained increasing support throughout Europe by exploiting fears and inciting resentment" (Rudiger and Spencer, 2003: 12). Member States seemed unable to respond effectively to such crisis. The latest influx of newcomers reopened the debates on border controls and humanitarian aid, but also on the social and economic challenges that need to be addressed. The article investigates the socio-economic impact of the refugees in EU, with a focus on the costs and benefits, starting from the assumption that the short and medium term costs will be shadowed by the long term benefits.
\end{abstract}

Keywords: refugees, migration of third country nationals, migration out of choice, migration out of necessity, cost-benefit analysis.

\section{Preliminary}

The latest inflows of refugees should not be understood as new or unexpected. The need to escape conflict and persecution from a war-torn land, as an act of despair or an attempt to survive has always led people to use migration, as an out of necessity strategy ${ }^{1}$. However, in the last two years we witnessed huge influxes of refugees in Europe. According to UNHCR, "an estimated

\footnotetext{
${ }^{1}$ Migration out of choice and migration out of necessity are mainly analysed in the context of the migration development nexus.
} 
number of 362,000 refugees and migrants risked their lives crossing the Mediterranean Sea in 2016, with 181,400 people arriving in Italy and 173,450 in Greece. In the first half of 2017, over 105,000 refugees and migrants entered Europe". This journey is a dramatic one, with more than 2,000 deaths on the sea. All these figures have an emotional impact, on both refugees as well as receiving communities, and media contributed in putting a face on suffering, as we accept that behind migration statistics there are ... people!

The data gathered by the European Commission reveals that the asylum applicants admitted in host countries originate mainly from Syria, Iraq and Afghanistan, countries facing instability and poverty:

\section{Graph 1. Recognition rate for asylum applications in the EU, by citizenship}

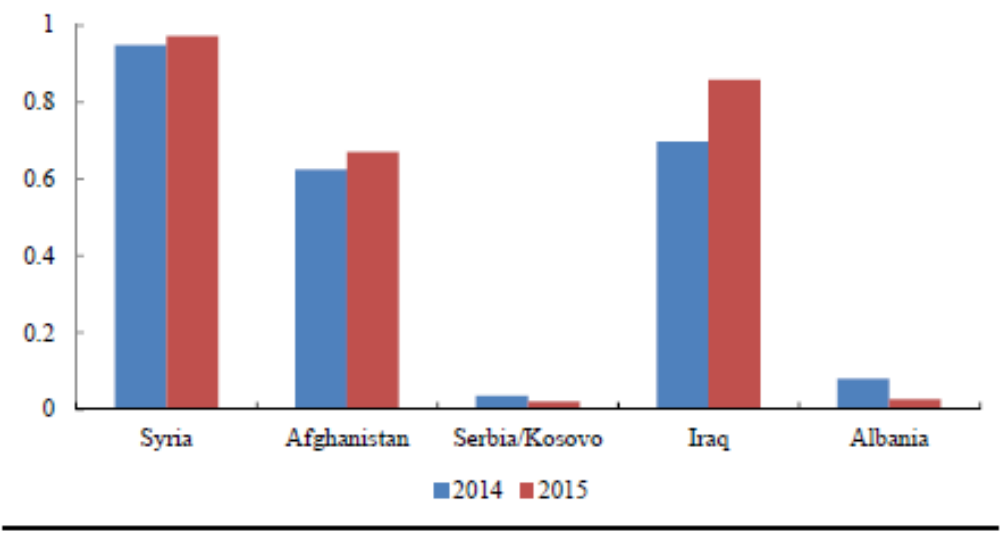

Source: European Commission

According to the data provided this year by Eurostat, "the number of persons seeking asylum from non-EU countries in the EU 28 during the second quarter of 2018 was 137 000, a number around the levels recorded in 2014, before the peaks of 2015 and 2016" (Asylum Quarterly Report, 2018). The latest inflows of newcomers led to some extreme approaches adopted by many receiving countries, from negative media coverage to denied access to EU borders, as signs of a revival of Fortress Europe. Still, no one can ignore the following facts:

- Europe is facing an unprecedented number of newcomers, diverse in terms of educational background and skills, a challenge for any socio-economic integration programs; 
- Germany absorbed more refugees than any other country in the EU, in absolute terms. Still, on a per-capita basis, Sweden and Austria are the largest destination countries. In 2015, Germany adopted the highly criticized “open border" policy, taking in 890,000 refugees and receiving 476,649 formal applications for political asylum (Trines, 2017);

- In the latest inflows, a relevant part is represented by unaccompanied children, exposed to serious emotional and physical distress;

- Economic migrants are blended in the general inflows of refugees, so it is important to distinct between those in need for humanitarian support and those in search for a better life, who may return to their home countries, without endangering their lives;

- Most of the newcomers used illegal networks to access transit and destination countries in Europe;

- EU allocated more than 2 billion euros for humanitarian and non-humanitarian aid, in order to support refugees;

- Due to the forced nature of their migration and the traumatic experiences frequently associated with it, many refugees suffer from psychological strain, a topic barely included in any host country intervention programs;

- Despite the criticism of inefficiency, in the last 20 years, EU applied high standards in terms of asylum and border management.

\section{The socio-economic impact of the refugees in $\mathrm{EU}$}

In the following sections, we intend to balance the costs and benefits of the latest inflows of refugees in EU, starting from the assumption that, on the short term, costs overweight benefits, while on the long term, benefits prevail.

According to the Dublin Mechanism, asylum seekers can only apply for asylum in the first EU country they enter, and they risk deportation if they try to apply in another state. It is important to distinct between asylum seeker status and the refugee one, the latter, referring to "persons fleeing armed conflict or persecution, facing a situation that it's often so perilous and intolerable that they cross national borders to seek safety in nearby countries. These are people for whom denial of asylum has potentially deadly consequences" (UNHCR, 2016). Thus, the refugee status implies migration out of necessity in a real sense, while migrant status is a result of the migration out of 
choice. The controversy related to the uneven application of the Dublin regulations by different states heated the debate on the need for a profound reform of the entire system.

Most of the cost-benefit analysis of migration phenomena focused on the role of economic migrants, in the context of the migration-development nexus ${ }^{2}$, revealing the beneficial impact of labour migration on source countries, in terms of financial remittances, as well as non-financial remittances like transfers of new ideas, attitudes, behaviours, practices (migrants acting as change agents as they return to their home countries).

In order to tackle the issue of the costs and benefits of the latest refugee influx, we will refer to their impact on demography, labour market, especially employment, and fiscal contribution of the employed newcomers.

\section{The impact of the refugee inflows on demographics}

No one can deny that EU is facing alarming demographic trends. It is well known that Europe is dominated by a dramatic shrinking of the population, along with the aging phenomenon, costly in terms of granting social benefits, providing care and health services for the elderly, in the context of increasing aged dependency ratio (in EU 28 it reached $28.8 \%$ in 2015, and a projected ratio of $50.3 \%$ is expected for 2050, according to Eurostat (2016). Nevertheless, Europe witnesses a drop in the fertility rate ( 1.5 children per woman), along with low population growth (the lowest being registered in the main destination countries like Germany, Greece or Italy).

Moreover, according to 2015 Aging Report released by the European Commission, "in 2060 people will live (on average) six years longer than today. According to Eurostat statistics, the proportion of the population aged 65 or older will rise from $18.5 \%$ in 2014 to $28.4 \%$ in 2060. As a consequence, $[\ldots]$ the old-age dependency ratio is expected to decrease from around 4 to 1 in 2013 to 2 to 1 by 2060" (European Parliament, 2015: 4). It becomes clear that Europe is in real need of a demographic boost, therefore, the refugee influx with large proportion of young active persons should be considered a proper answer. The host countries need to start designing and implementing family oriented policies, supporting access to health and care services (previous inflows proved to be beneficial in terms of return on investments: once on the labour market,

\footnotetext{
${ }^{2}$ Probably, the most relevant contributions belong to Papademetroiu and Martin, 1991 and Van Hear and Sørensen, 2002.
} 
migrants contribute more to the social security system than they benefit from), educational services, including language training and support services for the newcomers to facilitate integration of the ones that do not plan any return to their home countries.

\section{The impact of the refugee inflows on labour market}

Regarding the labour market, migrants can fill important niches both in fast-growing and declining sectors of the economy, and contribute to labour-market flexibility. According to dual labour market theory, newcomers tend to fill the secondary labour market, characterized by "low skill levels, low earnings, easy entry, job impermanence, and low returns to education or experience" (Piore, 1970: 57). There is evidence in Denmark, that "the inflow of low-skilled immigrants may encourage natives to upgrade and adjust their jobs, taking advantage of immigrant-native complementarity as those two groups specialise in different occupations" (Foged and Per, 2015).

The so-called $3 D$ jobs (dirty, difficult and dangerous) are usually undertaken by the newcomers, risking de-skilling or social stigma.

In the same time, developed economies are in continuous search for skilled workforce, in the context of the alarming shrinkage of the active population.

Nevertheless, while analysing the education endowment of the refugees, UNHCR (2016b) reveals clear gaps in opportunity for the refugee children and youth:

- $61 \%$ of refugee children attend primary school (a clear risk for illiteracy), while at world's level, $91 \%$ of children attend primary school;

- $23 \%$ of refugee teenagers attend secondary school, while $84 \%$ of world's adolescents attend secondary school;

- Only $1 \%$ of refugee youth attend higher education, while $36 \%$ of world's youth is enrolled in higher education programs.

In order to address the problematic aspects of granting access to education for refugees, in 2015, it was launched The New York Declaration for Refugees and Migrants, signed by 193 countries, which emphasized education as a critical element of the international response to the present crisis. Newcomers should enjoy equal access to an education of good quality, to gain skills 
and flexible career routes. More active measure need to be properly implemented and intermediate assessments to be carried out to check the results against the set objectives.

The restricted or denied access to labour market in host societies are still problematic, and labour mobility remains limited, due to different migration policies adopted by EU member states, as synthetized in Box 1:

Box 1 Access to labour market in EU host countries (European Commission, 2016: 21)

A. full access without work permits - granted in Finland, Italy, Latvia, and Sweden

B. more restricted access (e.g. limited to certain sectors) as in Cyprus (where asylum seekers have access only to farming, animal food production, waste management, gas station and cleaning and food delivery) or in Austria, the UK, Bulgaria and Romania (where asylum seekers only have access to seasonal work, tourism, agricultural sector).

C. The so-called labour market check - in some countries (Austria, the UK, Luxembourg, Hungary, and Germany) asylum seekers may only work after this procedure is ended, Other criteria apply in the Netherlands, such as time limitation (asylum seekers are allowed to work for 14 or 24 weeks per year and only if they stay in an open reception facility).

D. EU, EEA and legally residing third-country nationals may all be prioritised over asylum seekers when filling a post.

The need for long term investments in educational and skill attainment is clear, in order to grant refugees access to labour market in the host countries, meaning access to genuine socio-economic integration.

A 2016 report launched by OECD stated that "refugees represent one of the most vulnerable groups of migrants on the labour market.... It takes refugees up to 20 years to have a similar employment rate as the native-born" (OECD 2016: 5-6), due to their incapacity to provide proper documentation that would clarify their level of education or skills, to their low host countries' language proficiency and limited access to up-skilling trainings. The refugees' employment rate tends to start at a lower point than any other migrant category, but what is remarkable is their catching up process, as the graph below shows: 


\section{Graph 2. Employment rate by different categories of migrants}

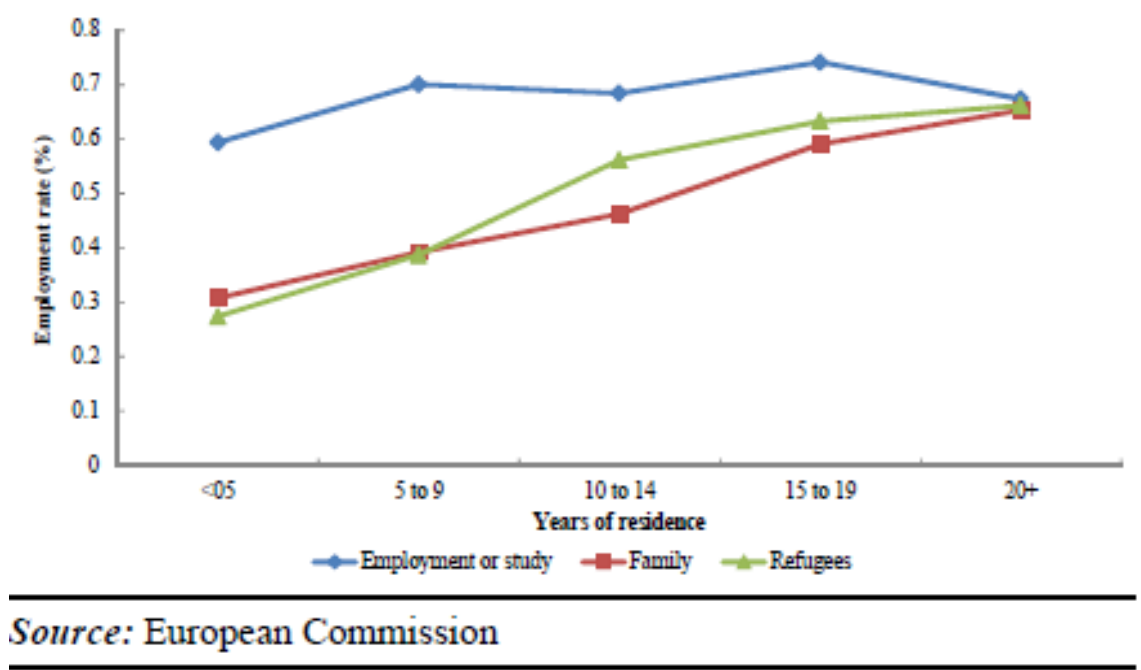

The economic migrants as well as the ones migrating for studies enjoy a higher employment rate, as expected. The ones in search for family reunification, as well as those with refugee status face the difficulties of finding jobs, but the latter perform better once they enter the host country labour market, a sign of commitment for integration in the country of destination.

As Safaya and Cramarenco (2016: 72) stated, a more balanced perspective on the newcomers' integration is highly needed, taking into consideration both costs (access to accommodation, jobs, education, culture, etc.) and opportunities (addressing the demographic disequilibrium, labour and skill shortages in fast-growing and declining sectors, as many refugees arrive with marketable skills, contributing to labour-market flexibility).

When analysing cost, we need to understand that a newcomer who receives benefits today can generate tax revenue tomorrow.

In terms of costs, Germany, the main EU receiving country for asylum claims, seems to spend more than 20 billion euros for accommodating the newcomers.

According to OECD (2017: 4), we can find various models of financial support for refugees, such as:

- Switzerland provides to cantons CHF 6000 per refugee, earmarked for refugee integration. 
- The United Kingdom developed time-dependent transfers, which decline with the number of years that have passed since a refugee arrived in the country - from GBP5 000 per person in their second year in the United Kingdom, to GBP1 000 per person in the fifth year.

- In France, the ministry of interior provides a lump sum of $€ 1000$ per asylum seeker to municipalities, to support the development of new reception facilities for asylum seekers, a clear attempt to de-centralize the support system.

- In Germany, the federal government provides a fixed sum of $€ 670$ per asylum seeker per month.

Despite the fear that the cost of refugees' integration programs are a huge burden to national budgets, 'a less comprehensive and less costly strategy might involve the risk of a long-term integration failure and the political costs of a massive political polarization' (Konle-Seidl and Bolits, 2016: 13)

Since 2011, in order to expand the limited knowledge on the refugees' integration in the host countries, EU and OECD carried out a general report on refugees' integration in Europe, the socalled Indicators of Immigrant Integration. In terms of employment, the main findings of the 2015 Report revealed:

- Income inequality is higher among immigrants than among the native-born;

- In 2013, the employment rate for immigrants reached 62\%, 3 percentage points lower than of the native born;

- Immigrants with high level of education struggle more to access jobs than their native born peers (the so-called invisible barriers built up by employers);

- $\quad 42 \%$ of highly educated immigrants perform low skilled jobs (risk of brain waste);

- $\quad 19 \%$ of the immigrants with lower incomes live in overcrowded households, compared to $8 \%$ of their native-bon peers.

Other reports (European Parliament, 2016; Errighi and Griesse, 2016) reveal that refugees tend to perform worse in the labour market than other migrant groups who have otherwise similar characteristics. Once recognized, refugees tend to perform better than other migrants, resulting in "higher wages and longer working hours for them after ten years than the other migrant groups of the same cohort. One reason for this is that refugees with a permanent residence status are less 
likely than other migrants to plan to return to their home country. Permanent immigration provides a greater incentive to invest in human capital than stays of a temporary nature." (European Parliament, 2016: 23).

Throughout 2016, several reports on Managing the refugees' crisis have been launched by the European Commission, in an attempt to analyse the most problematic issues such as granting access to newcomers, securing borders, preventing illegal migration, including the dismantle of smuggling networks and only one proposal with specific reference to integration of migrants with high education levels - a new DIRECTIVE OF THE EUROPEAN PARLIAMENT AND OF THE COUNCIL on the conditions of entry and residence of third-country nationals for the purposes of highly skilled employment. Most national integration programs generally consist of three main components: language training, orientation sessions and introduction to the culture of the host society and professional training and reorientation (contextual training), closely linked to labour market. These programs, which are compulsory to a certain extent, are, in most cases, individualized to the needs of immigrants (Safaya and Cramarenco, 2016: 81).

The medium and long term economic impact of the refugees depend mainly on their integration on the labour market. There is a clear need to reduce the restrictions imposed to refugees waiting for the asylum application to be processed, as well as a faster skills' equivalence systems. Granting early access to private and public jobs, by providing wage subsidies as a financial stimulus for employers, as well as to self-employment ${ }^{3}$ or jobs gained in the immigrants' business networks will speed up integration, and revenue generation. A relevant best practice is represented by the Swedish Introduction Program, accessible to all refugees, aged 20-64 years (active population), regardless of background or routes of entry. The plan comprises 3 support services: language training, employment preparation and social studies to provide a basic knowledge of Swedish society. Participation is voluntary, but comes with financial benefits that continue for six months after participants have found work, with the benefits being reduced in proportion to the time spent working, as a stimulus to find and preserve jobs (Swedish Integration Policy, 2016: 2)

\footnotetext{
${ }^{3}$ It became common knowledge that immigrants originating from Syria are highly oriented towards entrepreneurship, thus host countries should focus on reducing the administrative burden for start-ups, and granting fiscal incentives for new entrepreneurs.
} 
According to Ayar et al., 2016, the fear that taking care of the newcomers is costly is contradicted by available data - on a GDP-weighted basis, average budgetary expenses for asylum seekers in EU countries could increase by 0.05 and 0.1 percent of GDP in 2015 and 2016, respectively, compared to 2014. The same report states that the level of GDP is lifted by about $0.05,0.09$, and 0.13 percent for 2015,2016 , and 2017, respectively. The impact is quite different across countries, reflecting the asymmetric distribution of the asylum seekers relative to countries 'own population. By 2017, the largest impact is in Austria, with GDP rising by 0.5 percent, followed by Sweden ( 0.4 percent) and Germany ( 0.3 percent).

Moreover, the research conducted in 2017 by Kancs and Lecca revealed that, "although the refugee integration $[\ldots]$ is costly for the public budget, in the medium- to long-run, the social, economic and fiscal benefits may significantly outweigh the short-run refugee integration costs. Depending on the integration policy scenario and policy financing method, the annual long-run GDP effect would be $0.2 \%$ to $1.4 \%$ above the baseline growth, and the full repayment of the integration policy investment (positive net present value) would be achieved after 9 to 19 years (Kancs and Lecca, 2017:38).

Despite the efforts to quantify the fiscal impact of migrants as a large group, or even of refugees as a specific group, the data collected especially by OECD, cannot reveal a clear link between the migration stock and the net fiscal balance. Still, their fiscal contribution depends on the employment status, wage level, working age, etc. It is expected that the refugees' contribution is lower than the economic migrants' one, due the above mentioned barriers to labour market.

Still, using the QUEST methodology ${ }^{4}$, the European Commission made a simulation on the impact of newcomers on growth, public finances and labour markets. Two extreme scenarios were used:

1. High-skilled scenario, the skill distribution of migrants is assumed to match that of the EU;

2. Low-skilled scenario - all migrants are assumed to be low-skilled.

${ }^{4}$ QUEST - the global macroeconomic model the Commission uses for macroeconomic policy analysis and research. 
Table 1: Combined effects of increase in spending and labour force - EU

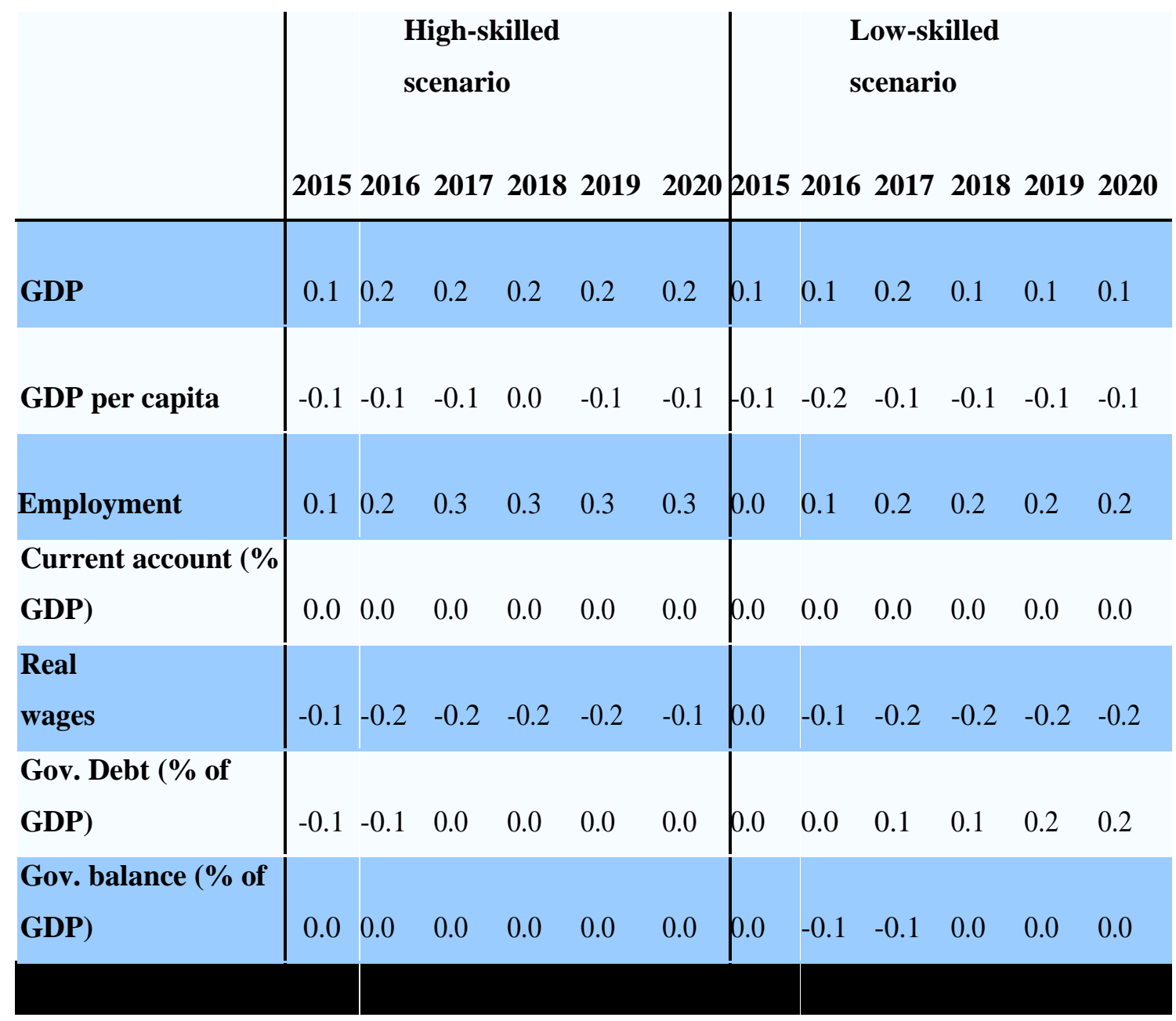

Level difference compared to base-line scenario.

Source: European Commission, 2016: 23

Regardless the scenario, in 2017 we may expect a $0.2 \%$ increase in GDP, but both scenarios reveal a small negative impact on GDP per capita and on real wages, no impact on current account and no impact on government balance in the case of the high-skilled scenario. Despite its limitations, the above mentioned exercise attempt to sketch the potential macroeconomic effects of the latest influx of new arrivals in EU, dismantling the exaggerated claims on severe negative impact on host countries 'economies. 
At both OECD and European Commission level, there is a clear understanding that overcoming the crisis has a lot, if not everything, to do with a genuine commitment of the host countries to the integration programs.

For raising awareness, OECD launched in 2016 a 10 lessons report for host countries facing the latest influx of new arrivals:

1. Begin activation and integration services as soon as possible, especially for groups of asylum seekers with likely high recognition rates (such as Syrian and Iraqi nationals).

2. Facilitate labour market access for applicants with high prospects of remaining, e.g. by abolishing possible 'labour-market tests' for humanitarian migrants that would show that no domestic worker could have filled the post before an employer is allowed to recruit an asylum seeker or a provisionally admitted humanitarian migrant.

3. Locate humanitarian migrants according to the availability of jobs, not housing. Notwithstanding a wish to distribute asylum seekers across and within countries and a tendency to place newly arrived in areas where housing is available, local labour-market conditions at arrival have proven to be a crucial determinant for lasting integration.

4. Avoid underutilisation of skills by documenting foreign qualification, work experience and skills earlier in the integration process. Many humanitarian migrants have higher skill levels than the average population in their country of origin (reflecting that the poorest can often not afford the costly journeys).

5. Customise integration policy instruments given the growing (skill) diversity among humanitarian migrants, as a one-size-fits-all approach may not be appropriate for refugees with different educational backgrounds, language skills and career prospects.

6. Identify mental and physical health issues early on to prevent any distress from turning into chronic and severe disorders and ensure that they are addressed in a targeted manner.

7. Speed-up access to education and training for unaccompanied minors as they are a particularly vulnerable group and, for most coming at the end of 
the age of compulsory schooling, risk ending up in neither employment, education or training.

8. Take into account future 'family reunification' when designing integration policies for humanitarian migrants as many of the newly arrived are adult men and have the right to family reunification.

9. Limit differences in access to integration services across a country. Integration primarily takes place at the local level.

10. For some humanitarian migrants (little or no prior education), sustained support will be needed. In their case the long term benefits are improbable.

This report may serve as a guideline for the simplification of the access procedures applied to the newcomers, as a clear reform of the national strategies as well as national integration programs became a must.

\section{Concluding remarks}

The recent refugee's crisis brought into attention that newcomers do not represent just a financial burden for the host countries, but contributors to improved demographics, labour market equilibrium, by performing jobs that natives refuse to take anymore, to the social security systems as tax payers, just to mention a few.

The free movement of labour is one of the most tangible benefits of European integration. Therefore, Europe needs a genuine comprehensive new strategy for both granting access and integration of the new comers. The focus on the humanitarian aid is understandable, but once accommodated in host countries, the refugees are in a clear need for access to language training, professional training, safe jobs and socio-cultural integration programs, as well as educational programs for their children. After leaving everything behind, they need protection and support mechanisms, in order to make a living, again!

In the nowadays migration turmoil, the integration of newcomers in Europe remains a project in the making, with opposite approaches, various needs to be met: the native workers to preserve their jobs and way of living, the second or third generation migrants to preserve their integration level and the newcomers to access a safe and stable life, outside their countries of origin. 


\section{References}

1. AYAR et al. (2016) The Refugee Surge in Europe: Economic Challenges. Available at: https://www.imf.org/external/pubs/ft/sdn/2016/sdn1602.pdf , [Accessed on 04.10.2018].

2. ERRIGHI, L. and GRIESS, J. (2016), The Syrian Refugee Crisis: Labour Market Implications in Jordan and Lebanon. Available https://ec.europa.eu/info/sites/info/files/file_import/dp029_en_2.pdf, [Accessed on 02.10.2018].

3. EUROPEAN COMMISSION (2016), An Economic Take on the Refugee Crisis. A Macroeconomic Assessment the EU. Available at: https://ec.europa.eu/info/sites/info/files/file_import/ip033_en_2.pdf [Accessed on 02.10.2018].

4. EUROPEAN COMMISSION (2016), Proposal for a DIRECTIVE OF THE EUROPEAN PARLIAMENT AND OF THE COUNCIL on the conditions of entry and residence of thirdcountry nationals for the purposes of highly skilled employment. Available at: https://ec.europa.eu/home-affairs/sites/homeaffairs/files/what-we-do/policies/europeanagenda-migration/proposal-implementationpackage/docs/20160607/directive_conditions_entry_residence_thirdcountry_nationals_highly_skilled_employment_en.pdf, [Accessed on 4.10.2018].

5. EUROPEAN PARLIAMENT (2015), Economic challenges and prospects of the refugee influx. Available

http://www.europarl.europa.eu/RegData/etudes/BRIE/2015/572809/EPRS_BRI(2015)57280 9_EN.pdf, [Accessed on 03.10.2018].

6. EUROPEAN PARLIAMENT (2016), Labour Market Integration of Refugees: Strategies and good practices. Available at: http://www.europarl.europa.eu/RegData/etudes/STUD/2016/578956/IPOL_STU(2016)57895 6_EN.pdf, [Accessed on 03.10.2018].

7. EUROSTAT statistics. Available at: http://ec.europa.eu/eurostat/tgm/table.do?tab=tableandinit=1 andlanguage=enandpcode=tsdde 511andplugin=1, [Accessed on 20.10.2018]. 
8. EUROSTAT (2018) - Asylum Quarterly Report, Available at https://ec.europa.eu/eurostat/statistics-explained/pdfscache/13562.pdf [Accessed on 30.10.2018].

9. FOGED, M. and PER, G. (2015), How immigrants and job mobility help low-skilled workers, Available at: http://voxeu.org/article/how-immigrants-and-job-mobility-help-low-skilledworkers, [Accessed on 06.08.2018].

10. GOVERNMENT OFFICES OF SWEDEN, Swedish Integration Policy. Available at: http://www.government.se/contentassets/b055a941e7a247348f1acf6ade2fd876/swedishintegration-policy-fact-sheet-in-english [Accessed on 06.08.2018].

11. KANCS d' ARTIS and LECCA, P. (2017) - Long-term Social, Economic and Fiscal Effects of Immigration into the EU: The Role of the Integration Policy. Available at: https://ec.europa.eu/futurium/sites/futurium/files/jrc107441_wp_kancs_and_lecca_2017_4.p df [ Accessed on 20.10.2018].

12. KONLE-SEIDL, R. and BOLTIS, G. (2016), Labour Market Integration of Refugees: Strategies and good practices. Available at: http://www.europarl.europa.eu/RegData/etudes/STUD/2016/578956/IPOL_STU(2016)57895 6_EN.pdf, [Accessed on 06.08.2018].

13. OECD (2015), Indicators of Immigrant Integration. Available at: http://www.keepeek.com/Digital-Asset-Management/oecd/social-issues-migrationhealth/indicators-of-immigrant-integration-2015-settling-in_9789264234024en\#.WhXrbFWnHIU [Accessed on 06.08.2018].

14. OECD (2016), How are refugees faring on the labour market in Europe?, Available at: file:///C:/Users/Proiect2/Downloads/KE-01-16-824-EN-N.pdf [Accessed on 20.10.2018].

15. OECD (2016), Making Integration Work: Refugees and others in need of protection, OECD Publishing, Paris. Available at: http://www.keepeek.com/Digital-AssetManagement/oecd/social-issues\%20migration-health/making-integration-work-humanitarian [Accessed on 20.10.2018].

16. OECD (2017), Migration policy debates. Available at: https://www.oecd.org/els/mig/migration-policy-debates-13.pdf [Accessed on 20.10.2018].

17. PAPADEMETROIU D. and MARTIN, P. L. (1991), The Unsettled Relationship: Labor Migration and Economic Development, Greenwood Publishing Group. 
18. PIORE, M. (1970), The Dual Labour Market: Theory and Implications in The State and the Poor, edited by Samuel H. BEER and Richard BARRINGER, pp. 55-59. Winthrop Publishers

19. RUDIGER, A. and SPENCER S. (2003), Social economic integration of migrants and ethnic minorities. Policies to combat discrimination. Available at: http://www.oecd.org/els/mig/15516956.pdf, [Accessed on 20.10.2018].

20. TRINES, S. (2017), Lessons from Germany's Refugee Crisis: Integration, Costs, and Benefits. Available at: https://wenr.wes.org/2017/05/lessons-germanys-refugee-crisis-integrationcosts-benefits [Accessed on 30.10.2018]

21. UNHCR (2016a), Migrant Rights. Available at: http://www.unhcr.org/news/latest/2016/7/55df0e556/unhcr-viewpoint-refugee-migrantright.html, [Accessed on 30.10.2018].

22. UNHCR (2016b), LEFT BEHIND REFUGEE EDUCATION IN CRISIS. Available at: http://www.unhcr.org/59b696f44.pdf, [Accessed on 06.08.2018 ].

23. UNHCR (2017), Europe situation. Available at: http://www.unhcr.org/europeemergency.html, [Accessed on 06.08.2018].

24. VAN HEAR, N. and NYBERG SORENSEN, N. (2002), The migration development nexus. Available at: http://publications.iom.int/system/files/pdf/migration_dev_nexus.pdf, [Accessed on 06.08.2018]. 